\title{
An Empirical Analysis of the Relationship Between IT Training Sources and IT Value
}

\author{
Pedro Soto-Acosta ${ }^{1}$, Isabel Martinez-Conesa ${ }^{1}$, and Ricardo Colomo-Palacios ${ }^{2}$ \\ ${ }^{1}$ Department of Management \& Finance, University of Murcia, Murcia, Spain \\ ${ }^{2}$ Computer Science Department, Universidad Carlos III de Madrid, Madrid, Spain
}

\begin{abstract}
Information technology (IT) training has been identifie as a key factor for the success of IT applications and the most frequently applied coping mechanism to handle changing IT. However, there is a question as to how IT training has to be conducted to obtain desired outcomes (higher levels of IT value). This paper analyses the presence of IT training sources used by firm and examines the influenc on IT business value. Here, IT training is studied according to three IT training sources: in-house IT training, outside IT training, and self IT training by employees. In addition, differences in IT training sources are analysed according to two contingency factors: business size and business industry. Results show a positive relationship between IT training sources (outside and self IT training) and IT business value and confir that IT training sources are positively related to business size and differ moderately by business industry.
\end{abstract}

Keywords Information technology; training; IT training; IT value; business value

\section{INTRODUCTION}

Today, the contribution of information technologies (ITs) to economies is unquestioned (Stehr, 2007). IT has been considered fundamental for the development of productivity and knowledge-intensive products and services. Jobs demanding IT skills from employees have increased exponentially all over the world. For example, it is estimated that today there are 4.2 million IT practitioners within the European Union (EU) and that approximately 180 million people are using ITs at work (CEPIS, 2007). In addition, in 2005 the share of employed persons in the EU using computers in their normal work routine exceeded 50\% for the first time (Eurostat, 2006).

New hardware, software, and mobile computational devices are constantly being launched, and it seems that this trend will continue in the future (Strohecker, 2005). Companies are committing more and more financial resources in order to acquire the latest technology available. This rapid growth faces a barrier, however; namely the capability of the labour force to understand

Address correspondence to Pedro Soto-Acosta, Department of Management \& Finance, University of Murcia, 30100 Espinardo, Murcia, Spain. E-mail: psoto@um.es and use IT applications. In this sense, IT investments often are underused, or are not used appropriately; this is mainly because employees do not possess sufficient IT skills to use them. This fact may cause IT to become obsolete before it pays off.

Most IT experts recognize that IT training is critical to achieve productive use of the technology (Yi \& Davis, 2001). This has also been confirmed by research. IT training has been identified as a key factor for the success of IT applications (McLean, Kappelman, \& Thompson, 1993). Sircar, Turnbow, and Bordoloi (2000) found a positive relationship between IT training and firm performance. Furthermore, investigations have shown a positive significant correlation between IT skills and efficient use of IT resources (Lee, Kim, \& Lee, 1995) and other studies' findings (e.g., Mata, Fuerst, \& Barney, 1995; Ravichandran \& Lertwongsatien, 2005) confirmed that IT skills may be source of competitive advantage. Thus, IT training is an important link to productive IT use, which in turn may affect IT value. Nonetheless, there is a question as to how IT training has to be conducted to obtain desired outcomes (higher levels of IT value).

The training process can be divided into three phases (Compeau, Olfman, Sein, \& Webster, 1995): (1) the initiation phase, which is concerned with needs assessments and the design and development of training materials; (2) the formal training and learning phase, which refers to the training methods used (lectures, computer-based, case studies, videotapes, etc.) and choice of training sources (outside, in-house, and self IT training by trainees); and (3) the post-training phase, which examines the long-term effects of training in terms of its influence on workplace behaviours. This research focuses on the second phase, the choice of training IT sources (in-house, outside, and self-training by employees), and presents three main contributions. First, it provides knowledge about the IT training sources used by firms. Second, the effect of IT training sources on IT business value is assessed. Finally, the presence of these training sources is analysed according to two contingency factors: business size and business industry.

The paper consists of seven sections and is structured as follows. Section 2 reviews the relevant literature. In section 3 , hypotheses are specified. Following that, the methodology 
used for sample selection and data collection is discussed in section 4 . Then, data analysis and results are examined. Finally, the paper ends with a discussion of research findings, limitations and concluding remarks.

\section{LITERATURE REVIEW}

\section{IT Training}

The literature on training suggests that training provide multiple benefits to firms. Training employees facilitates the updating of skills, leads to increased employee satisfaction (Acton \& Golden, 2003), increased employee commitment to the organization (Bushardt, Fretwell, \& Cumbest, 1994), and strengthens the organization's competitiveness (Hughey \& Mussnug, 1997; Burden \& Proctor, 2000). Although company commitment to training may lead to those potential benefits, there are many different categories and types of training (Switzer \& Kleiner, 1996; Huang, 2001; Mathews, Ueno, Periera, Silva, Kekal, \& Repka, 2001) and training delivery mechanisms (Acton \& Golden, 2003). With regard to IT training, Benamati and Lederer (2001) found that education and training was the most frequently applied coping mechanism to handle changing IT, though managers might question whether they use it sufficiently. Also, IT skills have been found to be a source of sustained competitive advantage. Mata et al. (1995) found that out of four IT attributes - capital requirements, proprietary technology, technical skills, and managerial IT skills_-only IT managerial skills are likely to be a source of competitive advantage. Ravichandran and Lertwongsatien (2005) found that intangible IT resources such as IT skills are critical determinants of how IT is deployed in the organization, which in turn can affect performance. In this sense, Sircar et al. (2000) found that IT training is positively correlated with a wide range of firm performance variables-sales, assets, equity, market share, and shares-, even more so than IT capital.

IT training can be provided in a number of forms and by a variety of sources. With regard to Compeau et al.'s (1995) three phases of training, this paper focuses on the second phase, the formal training and learning phase, and more specifically on training sources. Thus this research complements other studies analyzing the initiation phase (e.g., Nelson, Whitener, \& Philcox, 1995), the formal training and learning phase with regard to training methods (e.g., Laghos \& Zaphiris, 2007; Yi \& Davis, 2001), and the post-training phase (e.g., Kay \& Thomas, 1995). Nelson et al. (1995) consider that needs assessment sets the stage for effective end-user training. In this sense, they conducted a qualitative study implementing a content-levels framework to train end-users. Laghos and Zaphiris (2007) analyzed the social networks that form around self-taught e-learning communities. More specifically, they conducted a qualitative study with the aim of discovering what roles, groups and characteristics take place when there is no teacher to mentor the learning process. Yi and Davis (2001) examined whether the established behaviour-modeling approach to software training can be improved by adding a retention enhancement intervention as a substitute for handson practice. Results indicated that a combination of retention enhancement and practice let to significantly better cognitive learning than practice alone. Kay and Thomas (1995) developed a monitored system to study the use of the SAM text editor. The methodology offered the means for both low-cost tracking of user profiles for a system and a practical mechanism for constructing detailed individual user models.

\section{IT Business Value}

The measurement of IT business value is an important issue within the area of management information systems. In this sense, the value created by ITs can be measured, fundamentally, by subjective measures (e.g., Grover, Teng, Segars, \& Fiedler, 1998; Soto-Acosta \& Meroño-Cerdan, 2008; Tallon, Kraemer, \& Gurbaxani, 2000; Zhu \& Kraemer, 2005) or by using financial measures (e.g. Meroño-Cerdan \& Soto-Acosta, 2007; Zhu, 2004; Zhu \& Kraemer, 2002). The firsts normally use senior executives as key informants on subjective measures of performance. However, IT investments may provide benefits after a certain period but increase operating costs in the short term. In this sense, researchers (e.g. Soto-Acosta \& Meroño-Cerdan, 2008) argue that the business process should be the primary level of analysis. As a result, some researchers have given up on trying to correlate results with IT investments and suggest focusing on the actual processes that IT is supposed to enhance (Mukhopadhyay, Kekre, \& Kalathur, 1995).

To analyze and choose the business activities responsible for IT business value, the value chain analysis of Porter (1985) has been used. This approach has been broadly used in the IS literature to study the business value of IT. For instance, Mahmood and Soon (1991) developed a comprehensive model for measuring the potential impact of IT. Their model suggests that IT can help firms to improve performance along the value chain, on downstream dimensions, internal dimensions within the organization, and upstream dimensions. Following, Mahmood and Soon (1991), Tallon et al. (2000) separated IT business value intro downstream dimensions (sales support, customer services, and market expansions), internal dimensions (internal process, internal operation, and staff productivity), and upstream dimensions (coordination with suppliers and business partners). More recently, Zhu and Kraemer (2005) measured e-business value from upstream dimensions (impact on sales and impact on procurement) and internal dimensions (impact on internal operations). This research uses for measuring IT business value the effectiveness of upstream and internal online activities. The business value of these activities is discussed below.

Upstream online activities can potentially provide distinct value propositions to the firm. These come from the reduction of procurement and inventory costs, as well as strategic networks with suppliers that allow effective and efficient supply chain management (SCM). With regard to procurement costs, Kaplan 
and Sawhney (2000) indicated that buying in e-marketplaces considerably reduces transaction costs. With regard to strategic links and SCM, Internet technologies can enhance SCM decision making by enabling the collection of real-time information, and access to and analysis of this data in order to facilitate collaboration between trading partners in a supply chain. In this sense, Frohlich and Westbrook (2002) showed the importance of linking customers and suppliers together in tightly integrated networks.

The adoption of Internet technologies for internal activities can also provide value propositions to the firm. These come from the collaboration and exchange of knowledge between employees as well as through the availability of information for management and planning. With an Intranet's ability to provide intraorganizational communication at reduced cost, employees can distribute and communicate their ideas more readily, enabling them to be more involved in the decisionmaking process (Lai, 2001). Other alternatives come from the possibility of hosting discussion forums and/or repositories, where employees can create and share knowledge, which may be used for group learning. Using Internet technologies for the internal processing of commercial transactions can also create business value, since the automation of the sales process reduces overall load on staff supporting the customer, which allows staff to focus on more complex tasks or on exceptions instead of routine tasks (Meroño-Cerdan, Soto-Acosta, \& Lopez-Nicolas, 2008).

\section{DEVELOPMENT OF HYPOTHESES}

This section develops hypotheses for the present study, drawing on the existing information systems and e-business literature. Three relationships will be explored: IT training sources and business size, IT training sources and business industry, and IT training sources and IT business value.

\section{IT Training Sources and Business Size}

Business size has been consistently supported as an important organizational factor for technology adoption (Damanpour, 1992). For instance, Zhu, Kraemer, and Xu (2003) measured business size by the number of employees and demonstrated that larger size firms are more likely to adopt e-business. With regard to IT training, Westhead and Storey (1997) argued that employees in small and medium-size enterprises are less likely to receive training than their counterparts in larger firms, and they offer two explanations: ignorance and market-forces. The former considers that small businesses are not aware of the benefits of training and consequently provide less for their employees. The latter suggest that small businesses anticipate that the costs associated with training may exceed the benefits to be derived from it. Therefore, as larger businesses usually allocate greater financial, technological and personnel resources to IT training (Soto-Acosta, 2008), larger firms might be expected to have more IT training sources:
Hypothesis 1: The presence of IT training sources is positively related to business size

H1a: The presence of in-house IT training is positively related to business size.

$\mathrm{H} 1 \mathrm{~b}$ : The presence of outside IT training is positively related to business size.

H1c: The presence of self IT training is positively related to business size.

\section{IT Training Sources and Business Industry}

The ability to analyze separate industries is extremely important because of their vastly different characteristics, even though some relationships may be true across a broad spectrum of firms. In this sense, the industry in which a business operates has been found to influence the business' information processing requirements (Yap, 1990). Thus, firms belonging to the service industries, which rely on the processing of information, depend heavily on information systems (Premkumar \& King, 1994). In contrast, retail industries, which rely on the transfer of goods, may have a greater dependence on point-ofsale systems, whereas manufacturing industries depend more on specific information systems related to production such as ERP and CAD/CAM systems. These arguments suggest that firms from different industries may require distinct IT training sources. Thus, the following hypothesis is proposed:

Hypothesis 2: The presence of IT training sources differs by business industry

H2a: The presence of in-house IT training differs by business industry.

$\mathrm{H} 2 \mathrm{~b}$ : The presence of outside IT training differs by business industry.

H2c: The presence of self IT training differs by business industry.

\section{IT Training Sources and IT Value}

In the literature on information systems it is widely argued that EDI (Electronic Data Interchange) may enhance organizational efficiency. Mukhopadhyay et al. (1995) found that EDI enabled the effective coordination of material movements between manufacturers and suppliers, which resulted in significant cost savings and inventory reduction. Nonetheless, investing in IT is not a necessary nor sufficient condition for improving firm performance, since IT investments might be misused (Tallon et al., 2000). In this sense, IT assets cannot improve organizational performance if they are not used appropriately. However, when used appropriately IT is expected to create intermediary effects, such as IT being embedded in products and services, streamlined business processes, and improved decisions, which can be expected to have an influence on the performance of the firm (Ravichandran \& Lertwongsatien, 2005). Ravichandran and Lertwongsatien (2005) found that 
intangible IT resources such as IT skills are critical determinants of how IT is deployed in the organization, which in turn can affect performance. Similarly, Mata et al. (1995) suggested that IT might be a source of sustained competitive advantage and found that IT managerial skills are likely to be a source of competitive advantage. Moreover, Sircar et al. (2000) found that IT training expenditures are correlated significantly and positively with firm performance. Thus, the third hypothesis posits a positive relationship between IT training sources and IT value:

Hypothesis 3: There is a positive relationship between IT training sources and IT business value

H3a: There is a positive relationship between in-house IT training and IT business value.

$\mathrm{H} 3 \mathrm{~b}$ : There is a positive relationship between outside IT training and IT business value.

$\mathrm{H} 3 \mathrm{c}$ : There is a positive relationship between self IT training and IT business value.

\section{METHODOLOGY}

Data

The data source for the present study is the e-business E-mail: W@tch survey 2003, an initiative launched by the European Commission for monitoring the adoption of IT and e-business activity. Telephone interviews with decision-makers in enterprises were conducted in March and November 2003. The decision-maker targeted by the survey was normally the person responsible for IT within the company, typically the IT manager. Alternatively, particularly in small enterprises without a separate IT unit, the managing director or owner was interviewed.

In this study, the population considered was the set of all enterprises which are active at the national territory of Spain and which have their primary business activity in one of ten sectors considered. The sample drawn was a random sample of companies from the respective sector population with the objective of fulfilling strata with respect to business size. A share of $10 \%$ of large companies (250+ employees), $30 \%$ of medium sized enterprises (50-249 employees) and 25\% of small enterprises (10-49 employees) was intended. The number of firms totalled 1,010. As shown in Table 1,91.1\% of firms were small and medium-sized enterprises (less than 250 employees) and each sector considered had a share of around $10 \%$ of the total sample.

With regard to respondents' titles, $54.4 \%$ were IS managers, nearly $20 \%$ were managing directors, and $12.1 \%$ were owners. The dataset was examined for potential bias in terms of the respondents' titles. No significant differences were found, suggesting that the role of the respondents did not cause any survey biases.

\section{Measures of Variables}

This section describes the variables used for measuring the presence of IT training sources, business size, business industry and IT business value. The formulation and criteria for answering the questionnaire as well as prior research support are listed in the Appendix.

Business size: among several possible measures of firm size, such as annual revenue and number of employees, the latter was selected as a firm size indicator, following the tradition of the IT literature. For example, Brynjolfsson, Malone, Gurbaxani, and Kambil (1994) used number of employees as a control for firm size.

Business industry. This variable identified whether the business was operating at the manufacturing, services or commercial industry and was coded as a categorical variable.

IT training sources. Using a dichotomous scale, respondents assessed the use of three IT training sources: in-house, outside, and self IT training by trainees.

TABLE 1

Sample characteristics $(\mathrm{N}=1,010)$

\begin{tabular}{lccccc}
\hline Sample characteristics by sector, size, and respondent & & & \\
\hline Sector Name & $\%$ & $\mathrm{~N}$ & Number of employees & $\%$ & $\mathrm{~N}$ \\
Manufacture of textiles and leather & 10 & 101 & $1-9$ & 38.4 & 388 \\
Manufacture of chemicals & 9.9 & 100 & $10-49$ & 25.8 & 261 \\
Manufacture of electrical machinery & 9.9 & 100 & $50-249$ & 26.8 & 271 \\
Manufacture of transport equipment & 9.9 & 100 & More than de 249 & 8.9 & 90 \\
Crafts and Trade & 10.7 & 108 & Respondent title & $\%$ & $\mathrm{~N}$ \\
Retail & 9.9 & 100 & Owner/proprietor & 12.1 & 122 \\
Tourism & 9.9 & 100 & Managing director & 19.6 & 198 \\
Business services & 9.9 & 100 & Strategy development & 1.9 & 19 \\
Telecommunications \& computer services & 9.9 & 100 & Head of IT/DP & 22 & 222 \\
Health and social services & 10 & 101 & Other IT senior member & 32.4 & 327 \\
& & & Others & 12.1 & 122 \\
\hline
\end{tabular}


IT business value. As discussed earlier in section 2.3, the present research uses for measuring IT business value the effectiveness of upstream and internal online activities. Two constructs representing upstream and internal online activities were used. Since correctly measuring IT business value is important, an exploratory factor analysis (EFA), Cronbach's alpha calculation and confirmatory factor analysis (CFA) were carried out in order to improve constructs reliability and validity.

\section{ANALYSES AND RESULTS}

With regard to the presence of IT training sources, $66.9 \%$ out of all analyzed firms (676) was employing at least one type of IT training source. Table 2 shows detailed results. The use of self IT training by employees was the most frequently found form of IT training, with $51.8 \%$ of the total number of firms having it. In addition, this IT training source was found in $76.03 \%$ of all firms that had at least one type of IT training source. The second and third IT training sources in importance were outside and inhouse IT training, respectively. Less than $30 \%$ of all analyzed companies presented in-house IT training and $44.3 \%$ were using outside IT training.

Table 3 shows results for companies presenting more than one IT training Source. For companies using in-house IT training, it was found that $20.5 \%$ used also outside IT training and $19.5 \%$ self IT training by employees. With regard to firms using outside IT training, we found that $20.5 \%$ used inhouse IT training and $32.4 \%$ self IT training by employees as well. Furthermore, the three IT training sources were found in $15.44 \%$ of all analysed companies.

TABLE 2

Presence of IT training sources

\begin{tabular}{lcc}
\hline IT training source & $\begin{array}{c}\text { Total \% } \\
(\mathrm{N}=1010)\end{array}$ & $\begin{array}{c}\text { At least one IT } \\
\text { training source \% } \\
(\mathrm{N}=676)\end{array}$ \\
\hline In-house IT training & $26.8 \%$ & $39.64 \%$ \\
Outside IT training & $44.3 \%$ & $65.68 \%$ \\
Self IT training & $51.8 \%$ & $76.03 \%$ \\
No training & $33.1 \%$ & - \\
\hline
\end{tabular}

TABLE 3

Presence of more than one IT training sources

\begin{tabular}{lccc}
\hline IT training source & $\begin{array}{c}\text { On-house IT } \\
\text { training }\end{array}$ & $\begin{array}{c}\text { IT } \\
\text { training }\end{array}$ & $\begin{array}{c}\text { Self IT } \\
\text { training }\end{array}$ \\
\hline In-house IT training & - & $20.5 \%$ & $19.5 \%$ \\
Outside IT training & $20.5 \%$ & - & $32.4 \%$ \\
Self IT training & $19.5 \%$ & $32.4 \%$ & - \\
\hline
\end{tabular}

\section{Results for the First Hypothesis}

In order to test whether the use of IT training sources is influenced by business size, the latter was introduced as a four-level categorical variable, coding whether the business pertained to group 1 (between 1 and 9 employees), group 2 (between 10 and 49 employees), group 3 (between 50 and 249 employees) or group 4 (more than 250 employees).

As presented in Table 4, statistical differences (between the four size groups) at the $1 \%$ level were encountered for all the IT training sources (in-house, outside, self IT training by employees). Therefore, hypotheses $\mathrm{H} 1 \mathrm{a}, \mathrm{H} 1 \mathrm{~b}$ and H1c were supported.

\section{Results for the Second Hypothesis}

The second hypothesis postulated that IT training sources differ by business industry. Business industry was coded as a three-level categorical variable that represented whether the business belonged to the manufacturing, service or commercial industry. Results (see Table 5) showed that, within the sample, IT training sources were influenced by business industry for in-house $(\mathrm{p}=0,000)$ and self IT training by employees $(p=0.000)$, while for outside training differences by industry were not found $(\mathrm{p}=0.060)$. Through this analysis, hypotheses $\mathrm{H} 2 \mathrm{a}$ and $\mathrm{H} 2 \mathrm{c}$ found support, whereas $\mathrm{H} 2 \mathrm{~b}$ was not supported.

\section{Results for the Third Hypothesis}

The third hypothesis suggested a positive relationship between IT training sources and IT business value. The statistical technique used to test this hypothesis was the hierarchical multiple regression analysis.

To assess the business value of IT training sources, two constructs representing the value of upstream and internal online activities were used. Business industry and business size were introduced as control variables in order to avoid unexpected effects on IT business value. The former identified whether the business was operating at the manufacturing, services or commercial industry and was coded as a dummy variable. The latter was measured as the total number of employees and was coded as a continuous variable.

The basic econometric relationships may be specified as follows:

$$
\begin{aligned}
& \text { DV1 }=\mathrm{f}(\mathrm{INT}, \mathrm{OT}, \mathrm{ST}, \varepsilon), \text { and } \\
& \text { DV2 }=\mathrm{f}(\mathrm{INT}, \mathrm{OT}, \mathrm{ST}, \varepsilon),
\end{aligned}
$$

where INT stands for in-house IT training; OT denotes outside IT training; and ST represents self IT training by employees. DV1 and DV2 denote the dependent variables, upstream IT value and internal IT value, respectively. More specifically, the regression equations are: 
TABLE 4

IT training sources and business size

\begin{tabular}{|c|c|c|c|c|c|c|c|c|c|c|}
\hline \multirow[b]{2}{*}{ IT training source } & \multicolumn{2}{|c|}{$\begin{array}{c}\text { Group 1 } \\
(1 \leq \mathrm{E}<10)\end{array}$} & \multicolumn{2}{|c|}{$\begin{array}{c}\text { Group 2 } \\
(10 \leq \mathrm{E}<50)\end{array}$} & \multicolumn{2}{|c|}{$\begin{array}{c}\text { Group } 3 \\
(50 \leq \mathrm{E}<250)\end{array}$} & \multicolumn{2}{|c|}{$\begin{array}{l}\text { Group } 4 \\
(E \geq 250)\end{array}$} & \multicolumn{2}{|c|}{ Chi-squared test } \\
\hline & $\mathrm{N}$ & $\%$ & $\mathrm{~N}$ & $\%$ & $\mathrm{~N}$ & $\%$ & $\mathrm{~N}$ & $\%$ & $X^{2}$ & $\mathrm{p}$ \\
\hline $\begin{array}{l}\text { In-house IT } \\
\text { training }\end{array}$ & 74 & 19.2 & 69 & 26.5 & 90 & 33.5 & 35 & 40.2 & 25.37 & $0.000^{* *}$ \\
\hline $\begin{array}{l}\text { Outside IT } \\
\text { training }\end{array}$ & 118 & 30.8 & 110 & 42.1 & 155 & 57.4 & 61 & 69.3 & 69.85 & $0.000^{* *}$ \\
\hline Self IT training & 169 & 44.1 & 107 & 41.3 & 176 & 66.2 & 62 & 73.8 & 58.73 & $0.000^{* *}$ \\
\hline
\end{tabular}

Note: $\mathrm{E}=$ employees; * Significant at $\mathrm{P}<0.05$ level; ${ }^{* *}$ Significant at $\mathrm{P}<0.01$ level.

TABLE 5

IT training sources and business industry

\begin{tabular}{|c|c|c|c|c|c|c|c|c|}
\hline \multirow[b]{2}{*}{ IT training source } & \multicolumn{2}{|c|}{$\begin{array}{l}\text { Manufacturing } \\
\text { industry }\end{array}$} & \multicolumn{2}{|c|}{ Commercial industry } & \multicolumn{2}{|c|}{ Service industry } & \multicolumn{2}{|c|}{ Chi-squared test } \\
\hline & $\mathrm{N}$ & $\%$ & $\mathrm{~N}$ & $\%$ & $\mathrm{~N}$ & $\%$ & $X^{2}$ & $\mathrm{p}$ \\
\hline $\begin{array}{l}\text { In-house IT } \\
\text { training }\end{array}$ & 85 & 21.5 & 10 & 19.3 & 143 & 35.9 & 28.57 & $0.000^{* *}$ \\
\hline $\begin{array}{c}\text { Outside IT } \\
\text { training }\end{array}$ & 180 & 45.2 & 77 & 37.2 & 187 & 47.1 & 5.636 & 0.060 \\
\hline Self IT training & 181 & 46.4 & 96 & 46.6 & 514 & 51.8 & 17.04 & $0.000^{* *}$ \\
\hline
\end{tabular}

Note: *Significant at $\mathrm{P}<0.05$ level; ${ }^{* *}$ Significant at $\mathrm{P}<0.01$ level.

$$
\begin{aligned}
\mathrm{DV} 1= & \alpha+\beta 1 \mathrm{INT}+\beta 2 \mathrm{OT}+\beta 3 \mathrm{ST} \\
& +(\text { FirmSize }+ \text { IndustryDummies })+\varepsilon, \text { and } \\
\mathrm{DV} 2= & \alpha+\beta 1 \mathrm{INT}+\beta 2 \mathrm{OT}+\beta 3 \mathrm{ST} \\
& +(\text { FirmSize }+ \text { IndustryDummies })+\varepsilon,
\end{aligned}
$$

where $\alpha$ is the intercept; the $\beta$ i's are coefficients; and e is the residual term that captures the net effect of all unspecified factors.

The analysis was performed in two steps. The dependent variables were initially regressed on the control variables in step 1 . Then, in step 2 the three IT training sources were added. Regression results are summarized in Tables 6 and 7. Results in model 1 confirmed that the control variables employed do not explain the dependent variables. Model 2 showed that the direct effect of IT training sources upon IT business value was significant as the increment in the squared multiple correlation coefficient (R2) was statistically significant. The effect for outside IT training and self IT training by employees upon IT business value was positive and statistically significant (support for hypotheses $\mathrm{H} 3 \mathrm{~b}$ and $\mathrm{H} 3 \mathrm{c}$ was found), while for in-house
IT training the relationship was not significant (support for hypothesis $\mathrm{H} 3$ a was not provided).

\section{DISCUSSION}

The results indicate that IT training is widespread among Spanish firms, since $66.9 \%$ out of all analyzed companies was employing at least one type of IT training source. The most frequently found training source was self IT training by employees. Specifically, $51.8 \%$ of the sample was using self IT training. In addition, this type of training was found in almost $80 \%$ of firms that have at least one form of training. Moreover, $44.3 \%$ were using outside IT training and less than $30 \%$ of all analyzed companies presented in-house IT training. These results confirm that firms make extensive use of IT training and support previous research studies, suggesting the importance of IT skills and training. For instance, Benamati and Lederer (2001) found that education and training was the most frequently applied coping mechanism to handle changing IT. Mata et al. (1995) found that out of four IT attributes - capital requirements, proprietary technology, technical skills, and managerial IT skills-only 
TABLE 6

IT training sources and upstream IT value

\begin{tabular}{lcc}
\hline & MODEL 1 & MODEL 2 \\
\hline Manufacturing industry & -0.127 & -0.099 \\
Commercial industry & 0.017 & -0.044 \\
Number of employees & 0.066 & 0.045 \\
In-house IT training & & -0.029 \\
Outside IT training & & $0.208^{* *}$ \\
Self IT training & & $0.137^{*}$ \\
F-value & 1.663 & $3.72^{* *}$ \\
Adjusted R & 0.022 & 0.091 \\
$\Delta$ in R & & $0.069^{* *}$ \\
\hline
\end{tabular}

Significance levels: ${ }^{*} 0.01<\mathrm{p} \leq 0.05 ;{ }^{* *} \mathrm{p} \leq 0.01$.

TABLE 7

IT training sources and internal IT value

\begin{tabular}{lcc}
\hline & MODEL 1 & MODEL 2 \\
\hline Manufacturing industry & $-0.131^{*}$ & -0.106 \\
Commercial industry & 0.015 & 0.057 \\
Number of employees & $0.156^{* *}$ & 0.107 \\
In-house IT training & & 0.043 \\
Outside IT training & & $0.214^{* *}$ \\
Self IT training & & $0.147^{*}$ \\
F-value & $3.74^{*}$ & $7.84^{* *}$ \\
Adjusted R & 0.038 & 0.124 \\
$\Delta$ in R & & $0.105^{* *}$ \\
\hline
\end{tabular}

Significance levels: ${ }^{*} 0.01<\mathrm{p} \leq 0.05 ;{ }^{* *} \mathrm{p} \leq 0.01$.

IT managerial skills are likely to be a source of competitive advantage. Ravichandran and Lertwongsatien (2005) found that intangible IT resources such as IT skills are critical determinants of how IT is deployed in the organization.

The results showed, as hypothesized, that the presence of IT training sources is positively related to business size. This finding is not surprising, since larger businesses usually allocate greater financial, technological and personnel resources to the development and implementation of ITs (Soto-Acosta, 2008). This result confirms Westhead and Storey's (1997) argument, which suggested that employees in small and medium-size enterprises are much likely to receive training than their counterparts in larger firms, because management is not aware of the benefits of training and considers that the costs associated with training may exceed the benefits to be derived from it. In addition, this finding supports other recent research that analyzed ITs adoption according to business size. For instance, Zhu et al., (2003) measured business size by the number of employees and demonstrated that larger size firms are more likely to adopt e-business. Similarly, Teo and Pian (2004) found evidence of a positive link between web site adoptions and firm performance.
Furthermore, results demonstrate that the presence of IT training sources differs by business industry. The differences appeared for in-house and self IT training, where service firms presented higher levels of adoption, while for in-house IT training differences were not found. This result supports existing information systems literature. For instance, Goode and Stevens (2000) found business industry significant in the adoption of Internet connection, showing service industries to be the largest adopters, followed by retailers and then manufacturers.

Finally, the empirical results showed a positive relationship between IT training sources (outside and self IT training) and IT business value. The lack of relationship between in-house training and IT business value lead us to believe that this may be the reason why firms are using less this type of training. This findings confirm previous studies that found a positive relationships between IT skills/training and business value (Benamati \& Lederer, 2001; Mata et al., 1995; Ravichandran \& Lertwongsatien, 2005; Sircar et al., 2000) and suggest that firms may obtain better results if the use outside IT training or self IT training instead of in-house IT training.

\section{CONCLUSIONS, LIMITATIONS, AND FUTURE RESEARCH}

Most IT experts recognize that IT training is critical to achieve productive use of the technology. This statement is supported by research. For instance, IT training has been identified as a key factor for the success of IT applications and has been found to be correlated positively with a wide range of firm performance variables. Nonetheless, there is a question as to how IT training has to be conducted to obtain desired outcomes (higher levels of IT value). In this sense, IT training can be provided in a number of forms and by a variety of sources. With regard to Compeau et al.'s (1995) three phases of training, this paper focuses on the second phase, the formal training and learning phase, and more specifically on the choice of training sources (in-house, outside and self IT training). In this sense, the relationship between IT training sources and IT business value is tested on a large sample of Spanish firms from different sectors. Additionally, the presence of these training sources is analysed according to two contingency factors: business size and business industry. Broadly, this research offers several contributions: (1) it provides knowledge about the IT training sources used by firms; (2) it validates that the presence of IT training sources is positively related to business size and differs moderately by business industry; and (3) it shows a positive relationship between IT training sources (outside and self IT training) and IT business value.

While this study presents some interesting findings, it has some obvious limitations, which can be addressed in future research. First, the sample used was from Spain. It may be possible that the findings could be extrapolated to other countries, 
since economic and technological development in Spain is similar to other OECD Member countries. However, in future research, a sampling frame that combines firms from different countries could be used in order to provide a more international perspective on the subject. Second, the IT business value measures are subjective in the sense that they were based on Likert-scale responses provided by managers. Thus, it could also be interesting to include objective performance data for measuring IT business value. Third, the key informant method was used for data collection. This method, while having its advantages, also suffers from the limitation that the data reflects the opinions of one person. Future studies could consider research designs that allow data collection from multiple respondents within an organization. Fourth, this research takes a static, cross-sectional picture of IT training sources, which makes it difficult to address the issue of how IT training is conducted over years. A longitudinal study could enrich the findings.

\section{AUTHOR BIOS}

Pedro Soto-Acosta, is a Professor of Management at the University of Murcia (Spain). He holds a $\mathrm{PhD}$ in Management Information Systems (MISs) and a Master's degree in Technology Management from the University of Murcia. He was recipient of the Extraordinary Doctoral Award in Business Research. He received his BA in Accounting and Finance from the Manchester Metropolitan University (UK) and his BA in Business Administration from the University of Murcia. He attended Postgraduate Courses in Management Research at Harvard University (USA). His work has been published in journals such as the European Journal of Information Systems, the International Journal of Information Management and the International Journal of Electronic Business, among others.

Isabel Martinez-Conesa is a Professor of Finance and Accounting at the University of Murcia (Spain). She holds a $\mathrm{PhD}$ in International Financial Information. She was recipient of the Extraordinary Doctoral Award in Business Research. She also has been the director of seven dissertations about international financial analysis and accounting information system. Three of them were European Ph doctorate. Her work has been published in journals such as the European Accounting Review, the International Journal of Accounting, the Research in Accounting Regulation, the Spanish Journal of Finance and Accounting, and the European Business Review, among others.

Ricardo Colomo-Palacios is an Associate Professor at the Computer Science Department of the Universidad Carlos III de Madrid. His research interests include applied research in information systems, software project management, people in software projects and social and semantic web. He received his $\mathrm{PhD}$ in Computer Science from the Universidad Politécnica of Madrid (2005). He received his MBA from the Instituto de Empresa (2002). He has been working as a Software Engineer, Project Manager and Software Engineering Consultant in several companies including Spanish IT leader INDRA. He is also an Editorial Board Member and Associate Editor for several international journals and conferences, and he is the Editor-in-Chief of International Journal of Human Capital and Information Technology Professionals.

\section{REFERENCES}

Acton, T., \& Golden, W. (2003). Training the knowledge worker: a descriptive study of training practices in Irish software companies. Journal of European Industrial Training, 27 (2-4), 137-146.

Benamati, J. \& Lederer, A.L. (2001). Rapid information technology change, coping mechanisms, and the emerging technologies group. Journal of Management Information Systems, 17(4), 183-202.

Brynjolfsson, E., Malone, T.W., Gurbaxani, V., \& Kambil, A. (1994). Does information technology lead to smaller firms? Management Science, 40 (12), 1628-1644.

Burden, R., \& Proctor, T. (2000). Creating a sustainable competitive advantage through training. Team Performance Management, 6 (5-6), 90-97.

Bushardt, S.C., Fretwell, C., \& Cumbest, P.B. (1994). Continuous improvement through employee training: a case example from the financial services industry. The Learning Organization: An International Journal, 1 (1), $11-16$.

CEPIS (Council of European Professional Informatics Societies.). (2007). Thinking ahead on e-skills for the ICT industry in Europe. Brussels, Belgium.

Compeau, D., Olfman, L., Sein, M., \& Webster, J. (1995). End-user training and learning. Communications of the ACM, 38 (7), 24-26.

Damanpour, F. (2002). Organization size and innovation. Organization Studies, $13(3), 375-402$.

Eurostat. (2006). How skilled are Europeans in using computers and the Internet?. Statistics in focus. Luxemburg: European Commission.

Frohlich, M.T., \& Westbrook, R. (2002). Demand chain management in manufacturing and services: web-based integration, drivers and performance. Journal of Operations Management, 20 (6), 729-745.

Gold, A.H., Malhotra, A., \& Segars, A.H. (2001). Knowledge management: an organizational capabilities perspective. Journal of Management Information Systems, 18 (1), 185-214.

Goode, S., \& Stevens, K. (2000). An analysis of the business characteristics of adopter and non-adopters of world wide web technology. Information Technology and Management, 1 (2), 129-154.

Grover, V., Teng, J., Segars, A.H., \& Fiedler, K. (1998). The influence of information technology diffusion and business process change on perceived productivity: the IS executive's perspective. Information \& Management, 34 (3), 141-159.

Huang, T.C. (2001). The relation of training practices and organizational performance in small and medium size enterprises. Education and Training, 43 (8-9), 437-444.

Hughey, A.W., \& Mussnug, K.J. (1997). Designing effective employee training programmes. Training for Quality, 5 (2), 52-57.

Kaplan, S., \& Sawhney, M. (2000). E-hubs: the new B2B marketplaces. Harvard Business Review, 70 (1), 71-79.

Kay, J., \& Thomas, R.C. (1995). Studying long-term system use. Communications of the ACM, 38 (7), 61-69.

Laghos, A., \& Zaphiris, P. (2007). Social network analysis of self-taught e-learning communities. Int. J. Knowledge and Learning, 3 (4/5), 465-482.

Lai, V. (2001). Intraorganizational communication with intranets. Communications of the ACM, 44 (7), 95-100.

Lee, S.M., Kim, Y.R., \& Lee, J. (1995). An empirical study of the relationships among end-user information systems acceptance, training, and effectiveness. Journal of Management Information Systems, 12 (2), 189-202. 
Mahmood, M., \& Soon, S.K. (1991) A comprehensive model for measuring the potential impact of information technology on organizational strategic variables. Decision Sciences, 22 (4), 869-897.

Mata, F.J., Fuerst, W.L., \& Barney, J.B. (1995). Information technology and sustained competitive advantage: a resource-based analysis. MIS Quarterly, 19 (4), 487-505.

Mathews, B.P., Ueno, A., Periera, Z.L., Silva, G., Kekal, T., \& Repka, M. (2001). Quality training; findings from a European survey. The TQM Magazine, 13 (1), 61-71.

McLean, E.R., Kappelman, L.A., \& Thompson, J.P. (1993). Converging end-user and corporate computing. Communications of the ACM, 36 (12), 79-92.

Meroño-Cerdan, A., \& Soto-Acosta, P. (2007). External web content and its influence on organizational performance. European Journal of Information Systems, 16 (1), 66-80.

Meroño-Cerdan, A.; Soto-Acosta, P., \& Lopez-Nicolas, C. (2008). Analyzing collaborative technologies' effect on performance through intranet use orientations. Journal of Enterprise Information Management, 21 (1), 39-51.

Mukhopadhyay, T., Kekre, S., \& Kalathur, S. (1995). Business value of information technology: a study of electronic data interchange. MIS Quarterly, 19 (2), 137-156.

Nelson, R.R., Whitener, E.M., \& Philcox, H.H. (1995). The assessment of enduser training needs. Communications of the ACM, 38 (7), 27-39.

Porter, M.E. (1985). Competitive advantage. New York, NY: Free Press.

Premkumar, G., \& King, W.R. (1994). Organizational characteristics and information systems planning: an empirical study. Information Systems Research, 1 (3), 75-109.

Ravichandran, T., \& Lertwongsatien, C. (2005). Effect of Information Systems Resources and Capabilities on Firm Performance: A ResourceBased Perspective. Journal of Management Information Systems, 21 (4), 237-276.

Sircar, S., Turnbow, J.L., \& Bordoloi, B. (2000). A framework for assessing the relationship between information technology investments and firm performance. Journal of Management Information Systems, 16 (4), 69-97.

Soto Acosta, P. (2008). The e-Business performance measurement in SMEs. International Journal of Enterprise Network Management, 2 (3), 268-279.

Soto-Acosta, P., \& Meroño-Cerdan, A. (2008). Analyzing e-Business value creation from a resource-based perspective. International Journal of Information Management, 28 (1), 49-60.

Stehr, N. (2007). Societal transformations, globalisation and the knowledge society. Int. J. Knowledge and Learning, 3 (2/3), 139-153.
Stratman, J.K., \& Roth, A.V. (2002). Enterprise resource planning (ERP) competence constructs: two-stage multi-item scale development and validation. Decision Sciences, 33, 601-628.

Strohecker, C. (2005). Designing for sensing, sensibilities, and sense-making. Int. J. Knowledge and Learning, 3, 269-285.

Switzer, M., \& Kleiner, B.H. (1996). New developments in training teams effectively. Training for Quality, 4 (1), 12-17.

Tallon, P., Kraemer, K., \& Gurbaxani, V. (2000). Executives' perceptions of the business value of information technology: a processoriented approach. Journal of Management Information Systems, 16 (4), 137-165.

Teo, T.S.H., \& Pian, Y. (2004). A model for Web adoption. Information \& Management, 41 (4), 457-468.

Westhead, P., \& Storey, D. (1997). Training provision and the development of small and medium-sized enterprises, DfEE Research Report No. 26. London: DfEE/HMSO.

Wu, F., Mahajan, V., \& Balasubamanian, S. (2003). An analysis of e-business adoption and its impacts on business performance. Journal of the Academy of Marketing Science, 31 (4), 425-447.

Yap, C.S. (1990). Distinguishing characteristics of organizations using computers. Information \& Management, 18 (2), 97-107.

Yi, M.Y., \& Davis, F.D. (2001). Improving computer training effectiveness for decision technologies: behaviour modeling and retention enhancement. Decision Sciences, 32 (3), 521-544.

Zhu, K. (2004). The complementarity of information technology infrastructure and e-commerce capability: a resource-based assessment of their business value. Journal of Management Information Systems, 21 (1), 167-202.

Zhu, K., \& Kraemer, K.L. (2002). E-commerce metrics for net-enhanced organizations: assessing the value of e-commerce to firm performance in the manufacturing sector. Information Systems Research, 13 (3), 275-295.

Zhu, K., \& Kraemer, K.L. (2005). Post-adoption variations in usage and value of e-business by organizations: cross-country evidence from the retail industry. Information Systems Research, 16 (1), 61-84.

Zhu, K., Kraemer, K., \& Xu, S. (2003). Electronic business adoption by European firms: a cross-country assessment of the facilitators and inhibitors. European Journal of Information Systems, 12 (4), 251-268.

Zhu, K., Kraemer, K.L., Xu, S., \& Dedrick, J. (2004). Information technology payoff in e-business environments: an international perspective on value creation of e-business in the financial services industry. Journal of Management Information Systems, 21 (1), 17-54. 


\section{APPENDIX: MEASURES}

\begin{tabular}{|c|c|c|}
\hline Constructs and indicators & Description & Literature Support \\
\hline Outside IT training & $\begin{array}{l}\text { (b) Participation in IT training } \\
\text { offered by third parties? (Y/N) }\end{array}$ & $\begin{array}{l}\text { Campeau et al. (1995); Ravichandran } \\
\text { \& Lertwongsatien (2005); Sircar } \\
\text { et al. (2000); Yi \& Davis (2001) }\end{array}$ \\
\hline Self IT training & $\begin{array}{l}\text { (c) Employees can use some of their } \\
\text { working time for learning } \\
\text { activities }(\mathrm{Y} / \mathrm{N})\end{array}$ & $\begin{array}{l}\text { Campeau et al. (1995); Ravichandran } \\
\text { \& Lertwongsatien (2005); Sircar } \\
\text { et al. (2000); Yi \& Davis (2001) }\end{array}$ \\
\hline INV 2 & $\begin{array}{l}\text { What effect has the use of online } \\
\text { technologies for the internal } \\
\text { processing of commercial } \\
\text { transactions? (1-5) }\end{array}$ & $\begin{array}{l}\text { Stratman \& Roth (2002); Zhu } \\
\text { (2004); Zhu \& Kraemer (2005) }\end{array}$ \\
\hline INV 3 & $\begin{array}{l}\text { What effect has the use of online } \\
\text { technologies for the availability of } \\
\text { information for management and } \\
\text { planning? (1-5) }\end{array}$ & $\begin{array}{l}\text { Mata et al. (1995); Porter (1985); } \\
\text { Soto-Acosta \& Meroño-Cerdan } \\
(2008)\end{array}$ \\
\hline \multicolumn{3}{|l|}{ Upstream IT value } \\
\hline UPV3 & $\begin{array}{l}\text { What effect has online procurement } \\
\text { on the costs of logistics and } \\
\text { inventory? }(1-5)\end{array}$ & $\begin{array}{l}\text { Soto-Acosta \& Meroño-Cerdan } \\
\text { (2008); Wu et al. (2003); Zhu \& } \\
\text { Kraemer (2005) }\end{array}$ \\
\hline
\end{tabular}

Note. Y/N, dummy variable; $1-5$, five-point Likert-type scale. 